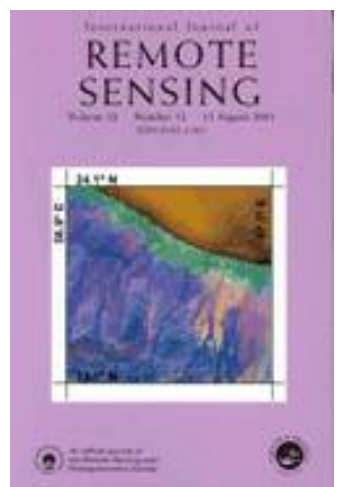

\title{
Influence of agricultural practices on micrometerological spatial variations at local and regional scales
}

\begin{tabular}{|r|l|}
\hline Journal: & International Journal of Remote Sensing \\
\hline Manuscript ID: & TRES-PAP-2005-0557.R3 \\
\hline Manuscript Type: & Research Paper \\
\hline Dute Submitted by the & 05-Dec-2007 \\
\hline Complete List of Authors: & $\begin{array}{l}\text { COURAULT, Dominique; INRA - UMR CSE } \\
\text { Jacob, Frédéric; IRD - UMR LISAH } \\
\text { Benoit, Violaine; INRA - UMR CSE } \\
\text { Weiss, Marie; INRA - UMR CSE } \\
\text { Marloie, olivier; INRA - UMR CSE } \\
\text { Hanocq, Jean-FrançOis; INRA - UMR CSE } \\
\text { FILLOL, Erwan; INRA - UMR CSE } \\
\text { OLIOSO, Albert; INRA - UMR CSE } \\
\text { DEDIEU, Gérard; CNES - UMR CESBIO } \\
\text { Gouaux, Pierrette; UPS - UMR CESBIO } \\
\text { Gay, Michel; EI PURPAN - LTGT } \\
\text { French, Andrew; USDA - ARS - ALARC }\end{array}$ \\
\hline Keywords: & $\begin{array}{l}\text { AGRICULTURE, EVAPOTRANSPIRATION, MODELLING, SURFACE AIR } \\
\text { TEMPERATURE }\end{array}$ \\
\hline Keywords (user defined): & remote sensing, microclimate, technical practices \\
\hline \hline
\end{tabular}

\section{๑) ScholarONE" Manuscript Central}



Catch line (head of first page only) International Journal of Remote sensing
Running heads D. Courault, F. Jacob, V. Benoit, M. Weiss, O. Marloie, JF. Hanocq, E. Fillol, A. Olioso, G. Dedieu, P. Gouaux, M. Gay, A. French. Impact of agricultural practices on micrometeorology

8 Article Type : Research Article

9

10

D. COURAULT ${ }^{1 *}$, F. JACOB ${ }^{2 \ddagger}$ J.F. HANOCQ ${ }^{1}$, E. FILLOL ${ }^{1}$, M. GAY ${ }^{4}$, A. FRENCH ${ }^{5}$.

\section{Influence of agricultural practices on micrometerological spatial variations at the local and regional scales}

1 UMR CSE, Domaine St Paul, site Agroparc, 84914 Avignon, France.

2 UMR LISAH, 2 place Viala, 34000 Montpellier, France.

3 UMR CESBio, 18 avenue E. Belin, 31401 Toulouse Cedex 9, France.

4 EI Purpan, 75 voie du TOEC, 31076 TOULOUSE Cedex 3, France.

5 U.S. ALARC, USDA/ARS, 21881 N. Cardon Lane, Maricopa, AZ 85239, USA.

$25 *$ Corresponding author. courault@avignon.inra.fr

$26 \neq$ Previously EI Purpan, Toulouse

28 Keywords: micrometeorology, cultural practices, high spatial resolution, remote 29 sensing, spatialised energy balance model. 
1 Abstract: Soil - vegetation - atmosphere transfers significantly influence interactions

2 and feedbacks between vegetation and boundary layer, in relation with plant phenology

3 and water status. The current study focused on linking micrometeorological conditions

4 to cultural practices at the local and regional scales (lower than $100 \mathrm{~km}^{2}$ ), over an

5 agricultural region in South Western France. This was achieved considering observation

6 and modelling tools designed for characterizing spatial variabilities over land surfaces.

7 These tools were the ASTER high spatial resolution optical remote sensing data, and the

8 SEBAL spatialised surface energy balance model. Surface bidirectional reflectance and

9 brightness temperature were first derived from ASTER data through solar and thermal

10 atmospheric radiative transfer codes, and next used to infer surface radiative properties

11 required for model simulations. Assessing model consistency in terms of air temperature

12 simulations gave satisfactory results when intercomparing against weather station data,

13 although basic model assumptions were not systematically verified in terms of spatial

14 variability. Next, spatialised simulations of evapotranspiration and air temperature were

15 analysed at the regional and local scales, in relation with pedology, land use, and

16 cultural practices. It was shown model estimates were consistent with the considered

17 crops and the related cultural practices. Irrigation appeared as the main factor amongst

18 others (soil, landuse, sowing date...) explaining the micrometeorological variability.

19 Although interesting and promising in terms of linking micrometeorological conditions

20 to cultural practices, the results reported here emphasized several difficulties, specially

21 about capturing subfield scale variability and monitoring the considered processes at an

22 appropriate temporal sampling. 


\section{Introduction}

3 Given land surface energy and water balance directly drive heat and moisture fluxes

4 within the planetary boundary layer, landscape structure, in terms of land use and soil /

5 vegetation distribution, can significantly influence regional climate (Pielke, 2001;

6 Stohlgren et al., 1998). Over agricultural landscapes, this influence is enhanced by

7 cultural practices such as irrigation that modify local temperature and water vapour

8 regimes. At the regional scale, De Ridder and Gallée (1998) showed that increasing

9 irrigated surfaces in previously arid regions can yield both substantial increases in 10 convectional precipitation during autumn and decreases in the temperature diurnal 11 range. At the local scale, which corresponds to that of crop monitoring and technical 12 itinerary (crop rotation, sowing dates, chemical and water supply), the influence of 13 cultural practices is also crucial through surface-atmosphere feedbacks (Ramankutty et 14 al., 2006 ; Courault et al., 2007). Thus, a time shift in the sowing date for a given crop 15 type may induce changes in surface roughness and Leaf Area Index (LAI), leading to 16 changes in surface fluxes and micrometeorological conditions such as 17 evapotranspiration and air temperature. Evapotranspiration is an important land surface 18 transfer which links soil and atmospheric water fluxes (Kustas et al., 2005). Air 19 temperature, which is strongly related to land surface thermal exchanges, influences 20 potential spread of pathogens (Schröder et al., 2006), but also vegetation functioning, 21 plant growth and therefore resulting biomass production (Courault and Ruget, 2001).

23 Classical measurements at the local scale, such as micrometeorological records, Bowen 24 ratio or eddy covariance, provide accurate estimates of micrometeorological variables 25 and surface fluxes, but the corresponding spatial extents are restricted. Using climatic 
1 data from weather stations faces both the inadequate spatial distribution and the low

2 network density, which makes difficult accounting for spatial heterogeneities. A

3 promising solution is using geostatistical approaches which interpolate local

4 measurements by considering environmental conditions such as land use within the

5 weather station neighbourhoods (Monestiez et al., 2001). Another promising solution is

6 synergistically using remote sensing data and modelling tools, for capturing and

7 characterizing landscape heterogeneities. Indeed, remotely sensed observations provide

8 information in a spatially distributed manner, which allows accounting for land surface

9 variabilities at different spatial scales (El Maayar and Chen, 2006 ; McCabe and Wood, 102006 ; Liu et al., 2006 ; Li et al., 2007).

12 The synergistic use of remote sensing and modelling benefits from several possibilities 13 for both observations and models. The use of remote sensing data collected over three 14 different spectral ranges allows retrieving several variables related to land surface 15 processes. Observations over the solar range are used for deriving albedo, leaf area 16 index, fractional vegetation cover, vegetation water and chlorophyll contents, and 17 fraction of absorbed photosynthetically active radiation (Weiss et al., 2002, Baret et al., 18 2008). Observations over the microwave domain provide access to soil moisture, 19 biomass, vegetation water content, and vegetation height (Wigneron et al., 2002 ; 20 Kellndorfer et al., 2004). Observations over the thermal domain allow inferring surface 21 temperature, which is linked to vegetation water status and root zone soil moisture 22 (Moran et al., 1994 ; Kustas and Norman, 2000 ; Crow and Kustas, 2005). The numerous 23 remote sensing based models proposed in the literature can be classified in two main 24 categories, regardless of their empirical or deterministic natures (Courault et al., 2005). 25 Non dynamical models provide instantaneous or daily values of surface energy fluxes, 
1 through forcing methods which use remote sensing for setting model variables (Kustas

2 and Norman, 1996; Jia et al., 2003 ; French et al., 2005 ; Sobrino et al., 2005 ;

3 Chehbouni et al., 2007). Dynamical models provide daily or hourly chronicles of surface

4 energy fluxes, and can benefit from assimilation methods which allow performing

5 calibration or constraining simulations (Olioso et al., 1999; Wigneron et al., 2002 ;

6 Demarty et al., 2005 ; Olioso et al., 2005 ; Er-Raki et al., 2007 ; Crow et al., 2007).

8 Regardless of models and observations, the existing approaches face the amount of 9 model parameters and variables to be documented, as compared to the available 10 information. This is particularly true with micrometeorological records. Such difficulties 11 can be overcome thanks to differential modelling approaches based on spatial or 12 temporal variabilities, which avoid using micrometeorological variables or allow retrieve 13 them indirectly. Differential methods based on temporal variabilities use hourly 14 variations of surface temperature and boundary layer structure (Anderson et al., 1997 ; 15 Mecikalski et al., 1999), or differences between current and extreme conditions (Su, 16 2002). Differential methods based on spatial variabilities use the correlation between 17 Normalized Difference Vegetation Index (NDVI) and near surface temperature gradient, 18 which is controlled by soil moisture (Moran et al., 1994 ; Gillies et al., 1997 ; Wang and 19 Takahashi, 1999 ; Friedl, 2002 ; Batra et al., 2006) ; or the correlation between surface 20 albedo and temperature, which is driven by evaporative and radiative processes 21 (Bastiaanssen et al., 1998a ; Roerink et al., 2000 ; Gomez et al., 2005). Amongst others, 22 the SEBAL model (Surface Energy Balance Algorithm for Land - Bastiaanssen et al., 23 1998a) was designed for retrieving wind speed and air temperature, by using the 24 correlation between surface albedo and temperature. SEBAL has been analysed and 25 validated through several studies (Bastiaanssen et al., 1998b; Jacob et al., 2002a ; 
1 Tasumi et al., 2003 ; French et al., 2005 ; Timmermans et al., 2007) and has been used

2 for water resource management at local and regional scales (Bastiaanssen, 2000;

3 Droogers and Bastiaanssen, 2002 ; Allen et al., 2005 ; Bastiaanssen et al., 2005).

5 With the launch in 2000 of the ASTER sensor (Advanced Spaceborne Thermal Emission

6 and Reflection Radiometer - Yamaguchi et al., 1998) onboard the Terra satellite,

7 differential methods based on spatial variability can benefit from high spatial resolution

8 optical remote sensing data with high quality. ASTER operates through three bands over

9 the visible - near infrared domain with a $15 \mathrm{~m}$ spatial resolution, six bands over the 10 shortwave infrared domain with a $30 \mathrm{~m}$ spatial resolution, and 5 bands over the thermal 11 infrared domain with a $90 \mathrm{~m}$ spatial resolution. Such observations offer new possibilities 12 for the mapping of surface biophysical and radiative variables, including albedo, 13 vegetation indices, leaf area index, fraction cover, vegetation water content, and surface 14 temperature (Anderson et al., 2004 ; Jacob et al., 2004 ; French et al., 2005). Operating 15 since 2001, ASTER has been intensively investigated for instrumental performances 16 (Arai, 2001 ; Matsunaga et al., 2001 ; Tonooka et al., 2003 ; Arai and Tonooka, 2005 ; 17 Sakuma et al., 2005 ; Tonooka et al., 2005), as well as for accuracies and consistencies 18 of land surface variable retrievals (Jacob et al., 2004 ; Gieske et al., 2004 ; Gillespie et 19 al., 2005 ; Jimenez-Munoz et al., 2006 ; Coll et al., 2007 ; Sobrino et al., 2007 ; Jimenez20 Munoz and Sobrino, 2007 ; Susaki et al., 2007).

22 The current study focuses on linking micrometeorological conditions (evapotranspiration 23 and air temperature) to cultural practices, in order to assess the influence of the later on 24 the former. This was achieved at the scale of a small agricultural region (around 25-30 $25 \mathrm{~km}^{2}$, scale which has not been often addressed), but also at the local scale. Considering 
1 both scales allowed accounting for several factors of influence such as soil type, land

2 use and agricultural practices. In order to perform these investigations, we selected two

3 widely used tools devoted to characterising the spatial variability of land surfaces: the

4 ASTER optical data and the SEBAL spatialized energy balance model. This required

5 previously assessing the quality of the ASTER observations in terms of land surface

6 variable retrievals, as well as that of the SEBAL simulations in terms of air temperature

7 and evapotranspiration. The study area was a small agricultural region under a

8 temperate climate in South Western France, located within an experimental site that has

9 supported several interdisciplinary projects. This study area included the experimental

10 Lamothe domain of the Purpan Graduate School of Agriculture, over which intensive

11 observations have been performed for several years, especially about cultural practices

12 such as land use, crop rotation, sowing date, water and nutrient supply...

14 The paper is organized as follow. Section II presents the basic concepts and the main 15 assumptions of the SEBAL model. Section III describes the experimental site. Section IV 16 highlights the ASTER data processing for deriving land surface variables to be used with 17 SEBAL. Model simulations are then analysed at regional and local scales in Section V. 18 This is achieved by first assessing consistencies of model assumptions and simulations, 19 and second linking simulated micro-meteorological conditions to cultural practices. 20 Finally, Section VI discusses the several difficulties such an approach faces.

\section{Model presentation}

24 SEBAL was originally developed by Bastiaanssen et al. (1998a), with the objective to 25 extract the maximum information from remote sensing data and therefore to use the 
1 minimum information from ground data. It was further improved and used through

2 different versions (Su et al., 1998 ; Jacob et al., 2002a ; Allen et al., 2005 ; Timmermans

3 et al., 2007). The study reported here relied on the SEBAL version improved by Su et al.

4 (1998). Basically, the model assumes the hydric spatial variability, which is captured

5 from solar and thermal remotely sensed observations, is significantly large over the

6 study area. Thus, wet and dry areas are discriminated through the radiative and

7 evaporative branches of the temperature - albedo diagram (Bastiaanssen, 1998a ;

8 Roerink, 2000). The evaporative branch is characterized, for lower albedo values, by an

9 increase of temperature as albedo increases, due to a decrease in surface moisture. The

10 radiative branch is characterized, for larger albedo values, by a decrease of temperature

11 as albedo increases, due to a decrease in absorbed solar irradiance.

12

13 Air temperature is spatialized assuming near surface temperature gradient is linearly 14 related to surface temperature. The linear relationship is calibrated from the energy 15 budget over the wet and dry areas within the study site (Figure 1). The largest 16 evaporation rates occur for the lowest temperatures over the wettest areas. They 17 correspond to negligible sensible heat fluxes and therefore negligible near surface 18 temperature gradients. Oppositely, the lowest evapotranspiration rates occur for the 19 largest temperatures over the driest areas. They correspond to negligible latent heat 20 fluxes, which allows inverting sensible heat flux expression to derive near surface 21 temperature gradient. The calibration of the linear relationship is then expressed as:

22

$23 T s-T a(z a)=\left[\frac{\left(R n-G_{0}\right) \cdot r_{a h}(Z a)}{\rho_{a} C_{p}}\right]_{\text {dry }} \times \frac{T s-T s_{w e t}}{T s_{d r y}-T s_{w e t}}$ 
1 where $C_{p}$ is specific heat; $\rho_{a}$ is air density; $z a$ is reference level ( $2 \mathrm{~m}$ above canopy) ; Ts

2 and $\mathrm{Ta}$ are surface and air temperatures respectively; $r_{a h}(z a)$ is aerodynamic resistance

3 between roughness length and reference level; $T s_{\text {wet }}$ and $T s_{d r y}$ are the lowest and largest

4 surface temperatures that occur over the wettest and driest areas, respectively. $R n$ is

5 net radiation, classically computed as the radiative budget over solar and thermal

6 domains, by using solar and thermal irradiances, albedo, broadband emissivity and

7 surface temperature. $G_{0}$ is soil heat flux, expressed as a fraction of net radiation through

8 an empirical relationship. The latter accounts for soil moisture effect on heat transfers

9 within soil, and for solar irradiance extinction through the aboveground vegetation

10 (Bastiaanssen et al., 1998a).

11

12

[Figure1]

13

14 Aerodynamic resistance $r_{a h}(z a)$ requires the knowledge of wind speed at reference level

$15 z a$ and roughness lengths for heat and momentum ( $z 0 h$ and $z 0 m$ respectively). Wind

16 speed at reference level is derived from an aggregation scheme over dry areas. This

17 scheme computes the regional aerodynamic resistance between the surface and the

18 blending height, which requires potential air temperature at the blending height. The

19 latter is usually fixed at $100 \mathrm{~m}$ above the surface, and corresponds to an altitude where

20 meteorological variables are supposedly homogenised. Roughness length for heat is set

21 as a tenth of roughness length for momentum ( $\mathrm{KB}^{-1}$ parameter fixed to 2.3). Roughness

22 length for momentum is a model input which retrieval will be presented further (Section

23 IV.2).

24

25 Finally, latent heat flux (or evapotranspiration) is computed as the residual of surface 
1 energy balance:

$3 L E=R n-H-G_{0}$

4

5 The model requires solar and thermal irradiances, which can be obtained from standard 6 meteorological measurements. Both variables do not significantly vary over a small 7 region (few tenths of $\mathrm{km}^{2}$ ), and can therefore be assumed homogeneous. The main 8 required SEBAL inputs are surface temperature, vegetation index, albedo, and 9 roughness length for momentum, which are inferred from optical remote sensing as 10 explained later in Section IV. Air potential temperature at the blending height can be 11 derived from radiosounding or weather forecast.

12

\section{III.Experimental setup}

\section{III.1.Study area}

17 The experimental site was located $30 \mathrm{~km}$ South West of Toulouse $\left(43.3^{\circ} \mathrm{N} ; 1.25^{\circ} \mathrm{E}\right)$. It 18 has been used as support for several national and international projects, which have 19 mainly focused on 1 / understanding interactions between crops and climate at the local 20 scale and 2/ modelling water and carbon budgets from the field to the landscape ${ }^{1,2}$. The 21 area was $50 \times 50 \mathrm{~km}^{2}$ sized. It included, amongst others, the Lamothe domain (Figure 2). 22 The latter is a $3 \times 3 \mathrm{~km}^{2}$ size agricultural domain from the Purpan Graduate School of 23 Agriculture, devoted to education and research. During the experiment, Lamothe 24 included large fields of corn, soybean, wheat and sunflower, water supplied or not.

\footnotetext{
SMOREX project http://www.cesbio.ups-tlse.fr/us/indexsmos.html

Sud Ouest project http://www.cesbio.ups-tlse.fr/us/sud_ouest.html
} 
[Figure 2]

\section{III.2.Ground based reference observations}

6 For each field within the domain, numerous records were collected and gathered in a

7 Geographical Information System database. These records included the cultural

8 practices such as crop variety, sowing date, schedule of nutrient and water supply (dates

9 and amounts). Accurate soil analysis were performed on each field of the Lamothe 10 domain. Textural differences appeared between the west and east parts. Western fields 11 were siltier, with deeper soils more favourable for crops than those located eastern. 12 Additionally, a field experiment was conducted from April to August 2005, to assess the 13 micrometerological spatial variability over Lamothe. For this, four micrometeorological 14 masts were set up on different crops (corn, wheat and sunflower, irrigated or not), to 15 collect measurements of wind speed, air temperature and humidity.

17 Meteorological measurements were those performed with the weather stations from the 18 Meteo - France synoptic network. Their locations are displayed on Figure 2. These 19 stations are automatic and follow the standard measurement protocol defined by the 20 World Meteorological Organisation. Thus air temperature is measured $2 \mathrm{~m}$ above the 21 surface over a non irrigated typical grassland without shelter or obstacles on vicinity.

\section{III.3.ASTER imagery}

25 As briefly explained in Introduction, the ASTER sensor is a multi-spectral instrument 
1 provided by the Japanese Ministry of International Trade and Industry, launched in

2 December 1999 onboard the NASA Earth Observing System (EOS) Terra satellite. Its

3 main characteristics are available at http://asterweb.jpl.nasa.gov/instrument.asp. The

4 sensor consists in three $63 \mathrm{~km}$ swath $\pm 3^{\circ}$ viewing scanners, with pointing capabilities of

$5 \pm 24^{\circ}$ for the visible - near infrared (Vis - NIR) scanner, and $8.5^{\circ}$ for the shortwave

6 infrared (SWIR) and thermal infrared (TIR) scanners. Vis - NIR scanner has three bands

7 with a $15 \mathrm{~m}$ spatial resolution, SWIR scanner has six bands with a $30 \mathrm{~m}$ spatial

8 resolution, and TIR scanner has 5 bands with a $90 \mathrm{~m}$ spatial resolution. ASTER

9 overpasses South Western France at 11:00 U.T. The temporal sampling is 16 days with

10 the same viewing configuration, or finer thanks to the pointing capabilities.

12 For the current study, more than 220 images were collected between 2000 and 2004 13 over a large portion of South Western France $\left(0-2^{\circ} \mathrm{E} ; 42^{\circ}-44^{\circ} \mathrm{N}\right)$. Only $17 \%$ were 14 cloudless, with three of them including the Lamothe domain on acquisition dates 15 13/05/2000, 30/06/2000 and 10/08/2003 (Figure 2). This underlined the difficulty to 16 operationally monitor crop from ASTER data only, although the study site was not a 17 preferential area of the ASTER mission.

\section{ASTER data processing for the retrieval of SEBAL inputs}

21 The whole flowchart for performing and analysing the SEBAL simulations is presented

22 on Figure 3. The first stages were related to the atmospheric corrections of ASTER 23 images. Next, different algorithms were used to retrieve the SEBAL model inputs: 24 surface albedo, NDVI, surface temperature, and roughness length for momentum. 25 Finally, SEBAL provided maps of air temperature and surface heat fluxes (H and LE). 
[Figure 3]

\section{IV.1.Atmospheric corrections}

6 ASTER images were pre-processed for removing atmospheric effects over the solar and

7 thermal spectral ranges, by using the 6S (Vermote et al., 1997) and MODTRAN

8 (Anderson et al., 2000) radiative transfer codes, respectively. These two radiative codes

9 required temperature, humidity and pressure profiles to characterize the atmospheric 10 status. No radiosounding was routinely performed near the study site: amongst the 11 seven locations within the French territory where such routine measurements are made 12 twice a day, the closest from the study site was located $200 \mathrm{~km}$ far away. Consequently, 13 we used simulated profiles from $\mathrm{ARPEGE}^{3}$ and $\mathrm{ECMWF}^{4}$ weather forecast models. The 14 profiles from both models were intercompared for the three dates of ASTER data 15 acquisition over the Lamothe domain. The profiles were quite similar, up to $35 \mathrm{~km}$, but 16 significant differences were observed near the surface on 10/08/2003. No validation 17 measurements were available for choosing between ARPEGE and ECMWF. However, we 18 selected the ARPEGE profiles since the first level was closer to the meteorological 19 measurements from the weather stations around the experimental area. Both 6S and 20 MODTRAN also required ozone profiles, which were obtained from the 6S climatological 21 database. The accuracy of this information was not considered as critical. Indeed, Jacob 22 et al. (2002c) showed inaccuracy on ozone profile was not significant over the ASTER 23 solar bands, in terms of surface reflectance. Besides, the ASTER thermal bands were 24 spectrally located outside the range of ozone perturbations (i.e. $9.5 \mu \mathrm{m}$ ).

3 ARPEGE is the French operational weather forecast model from Meteo France

4 ECMWF is the European Centre for Medium range Weather Forecast 
2 Finally, 6S required information about Aerosol Optical Thickness at $550 \mathrm{~nm}$

3 (AOT550nm). The latter could be inferred from sunphotometer measurements. Routine

4 data were freely available from the AERONET program (http://aeronet.gsfc.nasa.gov).

5 However, no AERONET measurements were available for the three dates of ASTER data

6 acquisition over the Lamothe domain, since no measurements were performed before

72001 from the nearest AERONET location. Therefore, we considered AOT estimates

8 inferred from MODIS ${ }^{5}$ data (http://delenn.gsfc.nasa.gov/ims-bin/pub/nph-ims.cgi). These

9 estimates were compared against AERONET measurements for the [2001-2004] period, 10 to assess their consistency. It was shown MODIS AOT550nm overestimated the 11 AERONET references, which was in agreement with the conclusions of Beal et al. (2007) 12 who reported a $20 \%$ overestimation from MODIS in relative. However, Jacob et al. 13 (2002c) showed an error on AOT550nm lower than $20 \%$ had no significant effect on the 14 ASTER retrievals of surface reflectance.

\section{IV.2.Estimating the model inputs}

18 Over the thermal domain, atmospheric corrections of ASTER data provided brightness 19 temperatures for each of the 5 ASTER bands, with a $90 \mathrm{~m}$ spatial resolution. Over the 20 solar domain, atmospheric corrections provided surface reflectances $(\rho)$ with a $15 \mathrm{~m}$ 21 spatial resolution, next aggregated to $90 \mathrm{~m}$ for consistency with the thermal domain. 22 NDVI was calculated as the normalized difference between red reflectance $\rho_{\text {red }}$ within 23 the ASTER band $2(0.63-0.69 \mu \mathrm{m})$ and near infrared reflectance $\rho_{\text {nir }}$ within the ASTER 24 band $3(0.78-0.86 \mu \mathrm{m})$ :

25

MODerate resolution Imaging Spectroradiometer 


$$
1 \quad N D V I=\frac{\left(\rho_{\text {nir }}-\rho_{r e d}\right)}{\left(\rho_{\text {nir }}+\rho_{\text {red }}\right)}
$$

2

3 Albedo ( $\alpha$ ) was computed using the Narrowband To Broadband (NTB) conversion 4 procedure: integrated value of albedo over the solar domain $([0.3-3] \mu \mathrm{m})$ was 5 expressed as a linear combination of waveband reflectances. Among the various 6 coefficient sets proposed in the literature, we chose that proposed by Jacob et al. 7 (2002b), since it gave satisfactory results when validated over agricultural surfaces. 8

$9 \alpha=-0.0595+0.2268 \rho_{\text {red }}+0.3055 \rho_{\text {nir }}$

11 The TES (Temperature Emissivity Separation) algorithm (Gillespie et al., 1998) was used 12 to retrieve surface radiometric temperature which is normalized from emissivity effects 13 (Norman and Becker, 1995). TES performances have been theoretically and 14 experimentally assessed by Gillespie et al. (1998) ; Schmugge et al. (1998, 2002) ; Payan 15 and Royer (2004) ; Jacob et al. (2004) ; Sobrino et al. (2006) ; French et al. (2007) ; Coll 16 et al. (2007) ; Sobrino et al. (2007). TES consists of solving the temperature / emissivity 17 separation, which is an ill posed problem, by retrieving the minimum emissivity value 18 from the spectral variability captured with the multispectral brightness temperatures 19 (here over the five ASTER TIR bands). An iterative process, which requires atmospheric 20 thermal irradiances (computed here from MODTRAN), provides emissivity for each 21 spectral band and therefore radiometric temperature. Next, a Narrowband To 22 Broadband (NTB) conversion was applied to derive broadband emissivity $\left(\varepsilon_{3-100 \mu m}\right)$ over 23 the [3-100] $\mu \mathrm{m}$ spectral range from ASTER waveband emissivities $\varepsilon_{\mathrm{\lambda} i}$, by using the 24 coefficient set proposed by Ogawa et al. (2002): 
$2 \varepsilon_{3-100 \mu m}=0.025 \varepsilon_{\lambda 10}+0.096 \varepsilon_{\lambda 11}+0.167 \varepsilon_{\lambda 12}+0.236 \varepsilon_{\lambda 13}+0.193 \varepsilon_{\lambda 14}+0.273$

4 where $\lambda_{\mathrm{i}}$ corresponds to the central wavelengths of ASTER TIR bands 10 to 14 .

6 Roughness length for momentum $(z 0 \mathrm{~m})$ could be derived either empirically from NDVI

7 or using expert knowledge from landuse. In the current study, we compared both 8 methods. The empirical derivation from NDVI consisted of using the relationship 9 proposed by Hatfield (1988) and Moran (1990):

10

$11 z 0 m=\exp (a+b . N D V I)$

12

13 where $\mathrm{a}$ and $\mathrm{b}$ coefficients depend on vegetation type and phenology (Bastiaanssen et 14 al., 1998a). They were set to the values proposed by Bastiaanssen et al. (1998a) for 15 vegetative areas $(a=-6.665$ and $b=6.38)$. The knowledge expert based procedure relied 16 on a landuse map derived from several SPOT images using a supervised classification 17 along with in-situ observations. Each landuse class was next characterized by a 18 vegetation height according to expert knowledge about crop development. Roughness 19 length was finally calculated as $1 / 8$ of vegetation height. Table 1 displays the differences 20 between the roughness length retrievals from the two methods. Unrealistic values were 21 observed when using Equation 6, especially for tall crops and maize. Therefore, we 22 considered the method based on landuse map and expert knowledge. 
1 The last SEBAL input to be considered was air potential temperature at the blending

2 height. The latter was derived from the ARPEGE atmospheric profiles.

3

$4 \quad$ V. Results

5

\section{V.1.Assessing model consistency}

8 Before analysing the relations between simulated micrometeorological conditions and

9 agricultural practices (Section V.2), it was necessary ensuring the simulations were 10 consistent. This was achieved assessing the relevance of the main SEBAL assumptions.

11 The first assumption was the potential discrimination between wet and dry surfaces 12 from the surface temperature - albedo diagram, in relation with evaporative and 13 radiative processes. The second point was the retrieval of air temperature in spatially 14 distributed manner.

16 Figure 4 displays the spatial correlation between surface albedo and temperature for 17 the three dates of ASTER data acquisition over the Lamothe domain. On 30/06/2000, we 18 could clearly separate evaporative and radiative branches. The albedo threshold value 19 corresponding to the inflection point could be determined manually or analytically, and 20 it was set to 0.22 . This date corresponded to a landuse which depicted a large hydric 21 spatial variability, since it included 1) well developed irrigated maize crops with large 22 evapotranspiration rates and 2) dry surfaces of harvested wheat fields with low 23 evaporation rates. However, it was difficult to define an albedo threshold value for the 24 two other dates. On 13/05/2000, the boundary between wet and dry areas was less clear 25 than on 30/06/2000, due to lower hydrological contrasts. There were less dry surfaces, 
1 wheat was not yet senescent, and maize irrigation was not yet initiated. The threshold

2 value was not easy to set, since surface radiometric temperature was almost constant

3 over the 0.18-0.22 albedo range. The most difficult situation occurred on 10/08/2003,

4 where no contrast could be distinguished. We just observed low variations of surface

5 temperature - albedo slope for albedo values between 0.15 and 0.22 . Nevertheless, this

6 date corresponded to a landuse that included both irrigated maize crops (surface

7 temperature around $35{ }^{\circ} \mathrm{C}$ ) and very dry wheat stubbles (surface temperature around

$850{ }^{\circ} \mathrm{C}$ ). This yielded suspecting the validity of the spatial correlation between surface

9 temperature and albedo during the extreme dry conditions of the summer 2003.

10 Numerous crops were very dry, or senescent, and depicted large values of surface 11 temperature and albedo. Another possible explanation was the spatial resolution.

12 Surface heterogeneities were smoothed at $90 \mathrm{~m}$ spatial resolution, due to the averaging

13 of surface albedo and temperature over mixed pixels. Some crops were irrigated using

14 sprinkler based systems with intra field turnovers up to 5 days. Subfield variabilities for

15 these crops could be distinguished from ASTER $15 \mathrm{~m}$ spatial resolution Vis - NIR data,

16 but not from $90 \mathrm{~m}$ spatial resolution TIR data (figure not shown). Therefore, contrasted

17 surfaces might appear as homogeneous, according to the field size and shape. Finally,

18 we selected a mean value of surface temperature between irrigated areas $\left(35^{\circ} \mathrm{C}\right)$ and

19 dry surfaces $\left(50^{\circ} \mathrm{C}\right)$, and we therefore fixed the threshold albedo to 0.2 on 10/08/2003.

23 In order to evaluate the consequences of the aforementioned difficulties when 24 discriminating wet and dry areas, we performed a sensitivity analysis for the air 25 temperature simulations from Equation 1. We assessed the influence of the chosen 
1 albedo threshold value on the linear relationship between surface and air temperature.

2 Three albedo threshold values were considered: $0.15,0.2$, and 0.25 . The 0.2 value

3 represented a mean value often encountered, while 0.15 and 0.25 represented two

4 extreme values. Besides, the 0.15 value could correspond to the first inflexion point

5 observed on third subplot of Figure 4. From these three different threshold values, three

6 simulations were made, given the other parameters were unchanged.

8 Figure 5 displays the three linear relationships between surface and air temperature we 9 obtained when considering different threshold values of albedo on 10/08/2003. The 10 intersection of the straight lines corresponded to air temperature at the blending height 11 (100 $\mathrm{m}$ above the surface), equal to $32{ }^{\circ} \mathrm{C}$ according to the ARPEGE simulated profile. It 12 corresponded to air temperature at $2 \mathrm{~m}$ above the surface, for stable conditions when 13 the temperature profile is constant with altitude. Outside this boundary value, we 14 observed significant variations in simulated air temperature according to the chosen 15 albedo threshold value. The larger the albedo threshold, the larger the slope was, 16 inducing closer air and surface temperatures. For instance, over a wheat - stubble field 17 with a $40{ }^{\circ} \mathrm{C}$ surface temperature, simulated air temperature was $32.6{ }^{\circ} \mathrm{C}$ with a 0.15 18 albedo threshold value, and $35{ }^{\circ} \mathrm{C}$ with a 0.2 albedo threshold value. On the other hand, 19 very little differences were observed between simulations from albedo threshold values 20 of 0.2 and 0.25 . This was explained by a lower occurrence of albedo values larger than $21 \quad 0.25$, which yielded similar values for the variables of interest in Equation 1.

22

25 The next stage consisted in assessing SEBAL simulations of air temperature. This was 
1 achieved at the regional scale by validating against measurements from weather

2 stations of the Meteo - France synoptic network (see Figure 2 for their localisation

3 within ASTER imagery). For this comparison, we considered the SEBAL averaged values

4 over a $3 \times 3$ pixel window centred on each station, which corresponded to 7 ha. This

5 window size was chosen to account for both the measurement footprint of the weather

6 station and the errors in the ASTER imagery registration. As shown by Table 2, the

7 obtained results were satisfactory, with a mean difference about $0.4{ }^{\circ} \mathrm{C}$.

[Table 2]

\section{V.2.Links between micrometeorology and agricultural practices}

13 Linking the simulated micrometeorological conditions to the agricultural practices was

14 firstly performed at the regional scale, by inter crossing the landuse map with that of air 15 temperature simulated from SEBAL, thus extracting the statistics for the main landuse 16 classes. We observed significant differences in air temperature according to the crop 17 types. For instance, the mean value of air temperature for maize was $35.4{ }^{\circ} \mathrm{C}$ on 18 10/08/2003, systematically lower than those for sunflower $\left(37.7^{\circ} \mathrm{C}\right)$ and wheat stubbles $19\left(38.7^{\circ} \mathrm{C}\right)$. Within some landuse classes such as maize, we also observed significant 20 variabilities due to the cultural practices such as water supply amount. Such information 21 on cultural practices was not available at large scale over the whole ASTER imageries. 22 Therefore, analysing the relationships between cultural practices and 23 micrometeorological conditions was next achieved at the finer scale.

25 The thorough analysis at the local scale relied on the numerous records which were 
1 available over the $3 \times 3 \mathrm{~km}^{2}$ size Lamothe agricultural domain. Figure 6 displays the

2 averaged values of air temperature and evapotranspiration for the different field within 3 the Lamothe domain on 10/08/2003. We observed a large spatial variability over the 4 different crops for both evapotranspiration (more than $230 \mathrm{~W} / \mathrm{m}^{2}$ ) and air temperature 5 (more than $4{ }^{\circ} \mathrm{C}$ ). It is worth noting the 2003 summer was extremely hot and dry, which 6 explained the low values of evapotranspiration observed for soybean and maize, and also 7 the very large air temperature values (more than $32^{\circ} \mathrm{C}$ ) for the all set of crops.

[Figure 6]

11 The observed spatial variations were mainly due to the different types of crop and 12 agricultural practice. For a same crop type, for instance maize as illustrated on Figure 6 13 (m1-4), we noted significant variabilities for evapotranspiration and and air 14 temperature. Irrigation, as expected, appeared as the first influence factor explaining 15 the largest differences, with variations in water supply up to $100 \mathrm{~mm}$ between the 16 different maize fields. These variations in water supply were correlated with both 17 evapotranspiration and vegetation amount. The fields with larger water supplies were 18 logically more developed. This can be observed on Figure 7 for maize fields $\mathrm{m} 1$ to $\mathrm{m} 4$, 19 with decreasing NDVI, increasing surface temperature, and therefore decreasing 20 evapotranspiration as shown by Figure 6. Oppositely, the fields with lower water 21 supplies were less developed and depicted lower evapotranspiration and NDVI values, 22 and larger surface temperature values, as indicated by Figure 7. 
1 Other factors could also explain the spatial variabilities obtained for air temperature and

2 evapotranspiration, such as differences in soil type, crop variety, and sowing date. Thus,

3 for a given crop, vegetation on western fields within the Lamothe domain (m1-s1-s2 on

4 Figure 6) were generally more developed than those located on the other fields. Indeed

5 the western soils were more favourable for crops (siltier) than eastern soils (more

6 clayey). This effect was particularly visible with the results obtained on 13/05/2000,

7 where large differences in evapotranspiration rates occurred between the maize fields

8 without irrigation (Figure 8). A one month shift for the sowing date might also explained

9 the differences observed for these maize fields.

|Figure 8]

13 We observed a significant variability over the small Lamothe domain in 2000 from the 14 SEBAL simulations of air temperature, up to $2.7^{\circ} \mathrm{C}$. This was consistent with that 15 observed from field data over various surfaces during the 2005 experiment: within the $1611: 00-15: 00$ U.T. period, up to $2.9^{\circ} \mathrm{C}$ were noted between wheat stubble and irrigated 17 maize. Given air temperature can significantly drive the vegetation activity throughout 18 the crop cycle and therefore the resulting yields, we finally compared both variables. 19 Table 3 shows the yields for the main fields of the Lamothe domain in 2003. A 20 correlation was observed between 2003 crop yields (Table 3) and air temperature on 21 10/08/2003 (Figure 6), particularly for the maize fields (m1-2-3). Knowing yields were 22 also driven by soil types, crop types and fertilization practices, more data would be 23 necessary for a deeper statistical analysis between crop yield and air temperature 24 variations. 
[Table 3]

\section{VI.Discussion}

5 The investigations reported here showed the pertinence of using high spatial resolution

6 optical remote sensing data along with spatialised energy balance modelling, in order to

7 link micrometerological conditions with agricultural practices. Though the obtained 8 results are of great interest, several difficulties have to be overcome.

10 The results underlined difficulties when identifying wet and dry areas on 10/08/2003.

11 This might result from extreme dry conditions in summer 2003, or from the the ASTER 12 TIR spatial resolution which was not fine enough for the observed landscape pattern. 13 Thus, spatialised models such as SEBAL are of interest for handling the spatial 14 variability of the considered processes, but they may be limited by the inadequateness 15 between the assumed spatial variability and that captured from optical remote sensing. 16 For the considered study site, which was typical of South Western France agricultural 17 areas, surface heterogeneities resulting from cultural practices such as irrigation could 18 not be well captured by the $90 \mathrm{~m}$ spatial resolution ASTER TIR imagery, because of the 19 involved fine spatial scales. There is consequently a need for finer spatial resolutions, in 20 the context of agricultural applications such as irrigation.

22 In the context of adequately monitoring the considered processes, another critical issue 23 is the temporal repetitiveness. For ASTER, the latter is 16 days in the same viewing 24 configuration, which is not fine enough for an operational crop monitoring. Further, the 25 actual repetitiveness is lower than the nominal one, because of cloud occurrence. This is 
1 a critical point over agricultural areas within South Western France, since less than 17\%

2 of the collected ASTER imageries were cloudless between 2000 and 2004. Though the

3 study area was not defined as preferential for systematic ASTER acquisition, it is

4 necessary filling the gap between two acquisitions. Geostationary satellites offer the

5 largest observation frequencies, but the spatial resolutions are too coarse regarding

6 landscape pattern. Recent works explored the simultaneous use of various spatial

7 resolutions, mostly combining observations over the Vis-NIR spectral range. However,

8 aggregation and desegregation techniques are more complex over the TIR domain,

9 while additional difficulties raise from non linear processes (Brunsell and Gillies, 2003 ;

10 Kustas et al., 2003).

11

12 These elements about space and time issues underline the need for finer spatial 13 resolution and temporal sampling over the optical domain. For the Vis-NIR spectral 14 range, ongoing missions such as FORMOSAT or Venus are devoted to the providing of 15 metric spatial resolution data, with temporal samplings about three days. Over the TIR 16 domain, there is no current possibility apart from the US Multispectral Thermal Imager 17 mission, which is restricted to military applications (Weber et al., 1999). This explains 18 the strong demanding for future missions with finer resolution TIR sensors, such as the 19 former European SPECTRA mission which yielded the Chinese SPECTLA mission 20 (Menenti, personal communication).

\section{VII.Conclusion}

24 This study focused on emphasizing the influence of agricultural practices on the spatial 25 variability of micrometeorological conditions, especially near surface air temperature 
1 and land surface evapotranspiration. For this, we used over a small agricultural region

2 in South Western France, two original tools designed for capturing and characterizing

3 the spatial variability of land surface hydric status. These tools were the ASTER high

4 spatial resolution optical sensor and the SEBAL spatialised energy balance model. We

5 assessed SEBAL for the mapping of both air temperature and evapotranspiration. The

6 comparison of air temperature retrievals against measurements from weather stations

7 underlined the good consistency of SEBAL simulations. Further, the simulated

8 meteorological conditions (in terms of air temperature and evapotranspiration) were

9 consistent with crop types and related agricultural practices. The largest spatial

10 variations in air temperature (up $4{ }^{\circ} \mathrm{C}$ over a small area for the drought event in summer

112003 ) and evapotranspiration (up to $250 \mathrm{~W} / \mathrm{m}^{2}$ ) were mainly driven by the water supply

12 for irrigated crops, as expected. The growing of the different crops induced also

13 variations of evapotranspiration and temperature. In spite of these interesting findings,

14 main difficulties were ascribed to the ASTER spatial resolution, which was not fine

15 enough for the observed landscape pattern. It is expected increasing spatial resolution

16 will allow overcoming such difficulties. This information will therefore be useful for

17 improving assessment of crop water status, either for irrigation scheduling, or for global

18 assessment of crop water use within an irrigated area.

\section{Acknowledgements}

21

22 This work was funded by different projects : MIP, inter regional project midi-Pyrénées-

23 Provence-Alpes Côte d'Azur, ECCO: PNBC national program 'ACI' managed by Cesbio.

24 The authors are grateful to the anonymous reviewers for their comments which have 25 improved this article. 


\section{References}

Allen, R.G., TAsumi, M., Morse, A., and Trezza, R., 2005, A Landsat-based energy balance and evapotranspiration model in Western US water rights regulation and planning. Irrigation and Drainage systems, 19, pp. 251-268.

Anderson, G., Berk, A., Acharya, P., Matthew, M., Bernstein, L., Chetwynd, J., Dothe, H., AdlerGolden, S., Ratkowski, A., Felde, G., Gardner, J., Hoke, M., Richtsmeier, S., Pukall, B., MeLlo, J., and JeONG, L., MODTRAN 4.0: radiative transfer modeling for remote sensing. In: Algorithms for multispectral, hyperspectral and ultraspectral imagery VI: Proceedings of SPIE. (2000) pp. 176-183.

Anderson, M.C., Norman, J.M., Diak, G.R., Kustas, W.P., and Mecikalski J.R., 1997, A twosource time integrated model for estimating surface fluxes using thermal infrared remote sensing. Remote Sensing of Environment, 60 pp. 195-216.

Anderson, M.C., Neale, C.C.M., Li, F., Norman, J., Kustas, W.P., Jayanthi, H., and Chavez, J.L., 2004, Upscaling ground observations of vegetation water content, canopy height, and leaf area index during SMEX02 using aircraft and Landsat imagery. Remote Sensing of Environment, 92 pp. 447-464.

Aral, K., 2001, Early results from the vicarious calibration of Terra/ASTER/SWIR. Advances in Space Research, 28(1) pp. 77-82.

Aral, K., and Tonooka, H., 2005, Radiometric performance evaluation of ASTER VNIR, SWIR, and TIR. IEEE Transactions on Geoscience and Remote Sensing, 43(12) pp. 2725-2732.

Baret, F., Weiss, M., and Lauvernet, C., 2008, Methodologies for inverting biophysical variables. In: Advances in Land Remote Sensing: System, Modeling, Inversion and Application (S. Liang Ed.), Springer, In press.

Bastiaanssen, W.G.M., Menenti, M., Feddes, R.A., and Holtslag, A.A., 1998a, A remote sensing surface energy balance algorithm for land (SEBAL): I. Formulation. Journal of Hydrology, 212-213(1-4), pp. 198-212.

Bastiaanssen, W.G.M., Pelgrum, H., Wang, J., Ma, Y., Moreno, J.F., Roerink, G.J., and Van Der $\mathrm{W}_{\mathrm{AL}}, \mathrm{T}$., 1998b, A remote sensing surface energy balance algorithm for land (SEBAL). 2. Validation. Journal of Hydrology, 212-213(1-4), pp. 213-229.

BastiaAnssen, W.G.M., 2000, Remote sensing for irrigated agriculture: examples from research and possible applications. Agricultural Water Management, 46, pp. 137-155.

Bastiannssen, W. G. M., Noordman, E. J. M., Pelgrum, H., Davids, G., Thoreson, B. P. , and Allen, R. G., 2005, SEBAL model with remotely sensed data to improve waterresources management under actual field conditions. Journal of Irrigation and Drainage Engineering, 131(1), pp. 85-93. 
Batra, N., Islam, S., Venturini, V., Bisht, G., and Jiang, L., 2006, Estimation and comparison of evapotranspiration from MODIS and AVHRR sensors for clear sky days over the Southern Great Plains. Remote Sensing of Environment, 103, pp. 1-15.

BÉal, D., Baret, F., Bacour, C., and Gu, X-F., 2007, A method for aerosol correction from the spectral variation in the visible and near infrared. Application to the MERIS sensor. International Journal of Remote Sensing, 28 (3-4), pp. 761 - 779.

Brunsell, N.A., and Gillies, R.R., 2003, Scale issues in land-atmosphere interactions: implications for remote sensing of the surface energy balance. Agricultural and Forest Meteorology, 117, pp. 203-221.

Caparrini, F., Castelli, F., and Entekhabi, D., 2005, Variational estimation of soil and vegetation turbulent transfer and heat flux parameters from sequences of multisensor imagery. Water Resources Research, 40, W12515, doi:10.1029/2004WR003358.

Chehbouni, A., Hoedjes, J., Rodriquez, J.C., Watts, C., Garatuza, J., Jacob, F., and Kerr, Y.H., 2007, Using remotely sensed data to estimate area-averaged daily surface fluxes over a semi-arid mixed agricultural land. Agricultural and Forest Meteorology, In press.

Coll, C., Caselles, V., Valor , E., Niclòs, C., Sánchez, J.M., Galve, J.M., and Mira, M., 2007, Temperature and emissivity separation from ASTER data for low spectral contrast. Remote Sensing of Environment, 110(2), pp. 162-175.

Courault, D., and Ruget F., 2001, Impact of local climate variability on crop model estimates in the south-east of France. Climate research, 18, pp. 195-204.

Courault, D., Seguin, B., and Olioso, A., 2005, Review about estimation of evapotranspiration from remote sensing data: from empirical to numerical modeling approach. Irrigation and Drainage systems, 19, pp. 223-249.

Courault, D., Drobinski, P., Brunet, Y., Lacarrere, P., and Talbot, C., 2007, Impact of surface heterogeneity on a buoyancy-driven convective boundary layer in light winds. Boundary-Layer Meteorology, 124(3), pp. 383-403.

Crow, W.T., and Kustas, W., 2005, Utility of Assimilating Surface Radiometric Temperature Observations for Evaporative Fraction and Heat Transfer Coefficient Retrieval. Boundary-Layer Meteorology, 115(1), pp. 105 - 130.

Crow, W.T., Kustas, W., and Prueger, J.H., 2007, Monitoring root-zone soil moisture through the assimilation of a thermal remote sensing-based soil moisture proxy into a water balance model. Remote Sensing of Environment, In press.

Demarty, J., Ottlé, C., Braud, I., Olioso, A., Frangi, J.-P., Gupta, H.V., and Bastidas, L.A., 2005, Constraining a physically based Soil - Vegetation - Atmosphere Transfer model with surface water content and thermal infrared brightness temperature measurements using a multiobjective approach. Water Resources Research, 41, W01011, doi:10.1029/ 2004WR003695. 115(1), pp. 105 - 130.

50

De Ridder, K., and Gallée, H., 1998, Land surface induced regional climate change in 
southern Israel. Journal of Applied Meteorology, 37, pp. 1470-1485.

Droogers, P., and BastiaAnssen, W., 2002, Irrigation performance using hydrological and remote sensing modeling. Irrigation and Drainage Engineering, 128 (1), pp. 11-18.

El MaAyar, M., and Chen, J.M., 2006, Spatial scaling of evapotranspiration as affected by heterogeneities in vegetation, topography, and soil texture. Remote Sensing of Environment, 102 (1-2), pp. 33-51.

Er Raki, S., Chehbouni, A., Hoedjes, J., Ezzahar, J., Duchemin, B., and Jacob, F., 2007, Assimilation of ASTER based ET estimates in FAO 56 model over olive orchards in a semi-arid region. Agricultural Water Management, in press.

French, A.N., Jacob, F., Anderson, M.C., Kustas, W.P., Timmermans, W., Gieske, A., Su, B., Su, H., McCabe, M.F., Li, F., Prueger, J., and Brunsell, N., 2005, Surface energy fluxes with the Advanced Spaceborne Thermal Emission and Reflection radiometer (ASTER) at the Iowa 2002 SMACEX site (USA). Remote Sensing of Environment, 99, pp. 55-65.

French, A.N., Schmugge, T.J., Ritchie, J.C. ,Hsu, A., Jacob, F., and Ogawa, K., 2007, Detecting land cover change at the Jornada Experimental Range, New Mexico, with ASTER emissivities. Remote Sensing of Environment, In press.

FRIEDL, M.A., 2002, Forward and inverse modeling of land surface energy balance using surface temperature measurements. Remote Sensing of Environment, 79, pp. 344354.

Gieske, A.S., Wubett, M.T., Timmermans, W. J., Parodi, G. N., Wolski, P., and Arneth, A., 2004, Temperature-emissivity separation with ASTER and LANDSAT 7 imagery validation on the fringe of the Okavango Delta, Botswana. In M. Owe, G. D'Urso, J. F. Moreno, \& A. Calera (Eds.). Remote Sensing for Agriculture, Ecosystems, and Hydrology $V$, Proceedings of the SPIE, 5232, pp. 489-498.

Gillespie, A.R., Rokugawa, S., Matsunaga, T., Cothern, S., Hook, S.J., and Kahle, A.B., 1998, A temperature and emissivity separation algorithm for Advanced Spaceborne Thermal Emission and Reflection radiometer (ASTER) images. IEEE Transactions on Geoscience and Remote Sensing, 36, pp. 1113-126.

Gillespie, A.R., Abrams, M., and Yamaguchi, Y., 2005, Scientific results from ASTER. Remote Sensing of Environment, 99(1-2), pp. 1-2.

Gillies, R.R., Carlson, T.N., Gui, J., Kustas, W.P., and Humes, K.S., 1997, A verification of the triangle method for obtaining surface soil water content and energy fluxes from remote measurements of the Normalized Difference Vegetation Index (NDVI) and surface radiant temperature. International Journal of Remote Sensing, 18(15), pp. 3145-3166.

Gomez, M., Sobrino, J.A., Olioso, A., and Jaсов, F., 2005, Retrieving evapotranspiration over the Alpilles / ReSeDA experimental site using airborne POLDER sensor and a thermal camera. Remote Sensing of Environment, 96, pp.399-408. 
HatField, J.L., 1988, Large scale evapotranspiration from remotely sensed surface temperature. In planning now for irrigation and drainage IR Div/ASCE, Lincoln, NE, July 18-21, pp. 502-509.

Jacob, F., Olioso, A., Gu, X., Su, Z., and Seguin, B., 2002a, Mapping surface fluxes using airborne visible, near infrared, thermal infrared remote sensing data and a spatialized surface energy balance model. Agronomie, 22, pp. 669-680.

Jacob, F., Weiss, M., Olioso, A., and French, A., 2002b, Assessing the narrowband to broadband conversion to estimate visible, near infrared and shortwave apparent albedo from airborne PolDER data. Agronomie, 22, pp. 537-546.

Jacob, F., Schmugge, T., Ogawa, K., French, A., and Ritchie, J, 2002c, The potentialities of ASTER to retrieve radiative properties over semi-arid regions. In : J. Sobrino (ed.), Proceedings of the First International Symposium on Recent Advances in Quantitative Remote Sensing, September 2002, Valencia, Spain, pp. 913-920.

Jacob, F., Petitcolin, F., Schmugge, T., Vermote, E., French, A., and Ogawa, K., 2004, Comparison of land surface emissivity and radiometric temperature derived from MODIS and ASTER sensors. Remote Sensing of Environment, 90 (2), pp. 137-152.

Jia, L., Su, Z., Van Den Hurk, B., Menenti, M., Moene, A., De Bruin, H.A.R., Baselga Yrisarry, J.J., Ibanez, M., and Cuesta, A., 2003, Estimation of sensible heat flux using the Surface Energy Balance System (SEBS) and ATSR measurements, Physics and Chemistry of the Earth, 28(1-3), pp. 75-88.

Jimenez-Munoz, J.C., Sobrino, J.A., Gillespie , A., Sabol, D., and Gustafson, T.G., 2006, Improved land surface emissivities over agricultural areas using ASTER NDVI, Remote Sensing of Environment, 103, pp. 474-487.

Jimenez-Munoz, J.C., and Sobrino, J.A., 2007, Feasibility of retrieving land-surface temperature from ASTER TIR bands using two-channel algorithms: a case study of agricultural areas, IEEE Geoscience and Remote Sensing Letters, 4(1), pp. 60-64.

Kellndorfer , J., Walker, W., Pierce, L., Dobson, C., Fites, J.A., Hunsaker, C. , Vona, J., and Clutter, M., 2004, Vegetation height estimation from Shuttle Radar Topography Mission and National Elevation Datasets. Remote Sensing of Environment, 93(3), pp. 339-358.

Kustas, W.P., and Norman, J.M, 1996, Use of remote sensing for evapotranspiration monitoring over land surface. Hydrological Sciences Journal 41(4), pp. 495-516.

Kustas, W.P., and Norman, J.M., 2000, A two-source energy balance approach using directional radiometric temperature observations for sparse canopy covered surfaces. Agronomy Journal 92(5), pp. 847-854.

Kustas, W.P., Norman, J., Anderson, M.C., and French, A.N., 2003, Estimating subpixel surface temperatures and energy fluxes from the vegetation index radiometric temperature relationship. Remote Sensing of Environment, 85, pp. 429-440. 
Kustas, W.P., Hatfield, J.H., and Prueger, J.H., 2005, The Soil Moisture-Atmosphere Coupling Experiment (SMACEX): Background, Hydro-meteorological Conditions, and Preliminary Findings. Journal of Hydrometeorology , 6(6), pp. 791-801.

Li, J., Kustas, W.P., Anderson, M.C., Prueger, J.H., and Scott, R.L., 2007, Effect of remote sensing spatial resolution on interpreting tower-based flux observations. Remote Sensing of Environment, In press.

Liu, Y., Hiyama, T., and Yamaguchi, Y., 2006, Scaling of land surface temperature using satellite data: A case examination on ASTER and MODIS products over a heterogeneous terrain area. Remote Sensing of Environment, 105(2), pp. 115-128.

Matsunaga, T., Nonaka, T., Samabe Y., Moriyama, M., Tonooka, H., and Fukasawa, H., 2001, Vicarious calibration of ASTER TIR and ETM+ thermal infrared band using ground targets. Salton Sea and Railroad Valley, June 2000. In: Proceedings of the Japanese Conference on Remote Sensing, 30, pp. 233-234.

McCABE, M.F., and Wood, F., 2006, Scale influences on the remote estimation of evapotranspiration using multiple satellite sensors. Remote Sensing of Environment, 105(4), pp. 271-285.

Mecikalski, J., Diak, G., Anderson, M., and Norman, J., 1999, Estimating fluxes on continental scales using remotely-sensed data in an atmospheric-land exchange model. Journal of Applied Meteorology, 38, pp. 1352-1369.

Monestiez, P., Courault, D., Allard, D., and Ruget, F., 2001, Spatial interpolation of air temperature using environmental context: application to crop model, Environmental \& Ecological Statistics, 8, pp. 297-309.

Moran, M.S., 1990, A satellite based approach for evaluation of the spatial distribution of evapotranspiration from agricultural lands. PhD thesis, University of Arizona, Tucson, USA, 185pp.

Moran, M.S., Clarke, T.R., Inoue, Y., and Vidal, A., 1994, Estimating crop water deficit using the relation between surface-air temperature and spectral vegetation index. Remote Sensing of Environment, 49, pp. 246-263.

Norman, J.M. and Becker, F., 1995, Terminology in thermal infrared remote sensing of natural surfaces. Remote Sensing Reviews, 12, pp. 159-173.

Olioso A., Chauki H., Courault D., and Wigneron JP., 1999, Estimation of evapotranspiration and photosynthesis by assimilation of remote sensing data into SVAT models. Remote Sensing of Environment, 68, pp. 341-356.

Olioso, A., Inoue, Y., Ortega-Farias, S., Demarty, J., Wigneron, J.-P., Braud, I., Jacob, F., Lecharpentier, P., Ottlé, C., Calvet, J.-C., and Brisson, N., 2005, Future directions for advanced evapotranspiration modeling: assimilation of remote sensing data into crop simulation models and SVAT models. Irrigation and Drainage Systems, 19(3-4), pp. 377-412. 
Ogawa, K., Schmugge, T., Jacob, F., and French, A., 2002, Estimation of broadband land surface emissivity from multi-spectral thermal infrared remote sensing. Agronomie, 22(6), pp. 695-696.

PAyan, V., and Royer, A., 2004, Analysis of the Temperature Emissivity Separation (TES) algorithm applicability and sensitivity. International Journal of Remote Sensing, 25, pp. 15-37.

Pielke, R.A., 2001, Influence of the spatial distribution of vegetation and soils on the prediction of cumulus convective rainfall. Reviews in Geophysics, 39, pp. 151-177.

Ramankutty, N., Delire, C., and Snyder, P., 2006, Feedbacks between agriculture and climate: An illustration of the potential unintended consequences of human land use activities, Land-use/land-cover change and its impact on climate. Global and Planetary Change, 54(1-2), pp.79-93.

Roerink, G.J., Su, Z., and Menenti, M., 2000, S-SEBI A simple remote sensing Algorithm to estimate the surface energy balance. Physics and Chemistry of the Earth (B), 25(2), pp. 147-157.

Sakuma, F., Ono, A., Tsuchida, S., Ohgi, N., Inada, H., Akagi, S., and Ono, H., 2005, Onboard calibration of the ASTER instrument. IEEE Transactions on Geoscience and Remote Sensing, 43(12), pp. 2715-2724.

Schmugge, T.J., Hook, S.J., and Coll, C., 1998, Recovering Surface Temperature and Emissivity from Thermal Infrared Multi Spectral Data. Remote Sensing of Environment, 65, pp. 121-131.

Schmugge, T., French, A., Ritchie, J., Rango, A., and Pelgrum H, 2002, Temperature and emissivity separation from multispectral thermal infrared observations. Remote Sensing of Environment, 83, pp. 121-131.

Schröder, W., Schmidt, G., and Hasenclever, J., 2006, Geostatistical analysis of data on air temperature and plant phenology from Baden-Württemberg (Germany) as a basis for regional scaled models of climate change. Environmental Monitoring and Assessment, 120(1-3), pp. 27-43.

Sobrino, J.A., Gomez, M., Jimenez-Munoz, J.C., Olioso, A., and Chehbouni, G., 2005, A simple algorithm to estimate evapotranspiration from DAIS data: Application to the DAISEX campaigns. Journal of hydrology, 315(1-4), pp. 117-125.

Sobrino, J.A., Jimenez-Munoz, J.C., Zarco-Tejada, P.J., Sepulcre-Cantó, G., and de Miguel, E. 2006, Land surface temperature derived from airborne hyperspectral scanner thermal infrared data. Remote Sensing of Environment, 102(1-2), pp. 99-115.

Sobrino, J.A., Jimenez-Munoz, J.C., Balick, L., Gillespie, A.R., Sabol, D.A. and Gustafson, W.T., 2007, Accuracy of ASTER Level-2 thermal-infrared Standard Products of an agricultural area in Spain. Remote Sensing of Environment, 106(2), pp. 146-153.

50 Stohlgren, T.J., Chase, T.N., Pielke, R.A., Kittel, T.G.F., and Baron, J.S., 1998, Evidence that 
local use practices influence regional climate, vegetation, and stream flow patterns in adjacent natural areas. Global Change Biology, 4, pp. 495-504.

Su, Z., Menenti, M., Pelgrum, H., van den Hurk, B., and Bastiannssen, W., 1998, Remote sensing of land surface fluxes for updating numerical weather predictions. In : Vaughan and Moleaar (Eds), Operational Remote sensing for Sustainable Development, Nieuwenhuis, Balkema, Rotterdam, 1999.

Su, Z., 2002, The Surface Energy Balance System (SEBS) for estimation of turbulent heat fluxes. Hydrology and Earth Science System, 6, pp. 85-99.

Susaki, J., Yasuoka, Y., Kajiwara, K., Honda, Y. and Hara, K., 2007, Validation of MODIS albedo products of paddy fields in Japan. IEEE Transaction on Geosciences and Remote Sensing, 45(1), pp. 206-217.

Tasumi, M., Trezza, R., Allen, R.G., and Wright, J.L., 2003, US validation tests on the SEBAL model for evapotranspiration via satellite. In: ICID Workshop on Remote Sensing of ET for Large Regions, 17 September 2003.

Timmermans, W.J., Kustas, W.P., Anderson, M.C., and French, A.N., 2007, An intercomparison of the surface energy balance algorithm for land (SEBAL) and the two-source energy balance (TSEB) modeling schemes. Remote Sensing of Environment, 108, pp. 369384.

Tonooka, H., Sakuma, F., Kudoh, M., and Imafune, K., 2003, ASTER/TIR calibration status and user-based recalibration. In: Proceedings of SPIE, 5234, pp. 191-201.

Tonooka, H., Palluconi, F., Hook, S., and Matsunaga, T., 2005, Vicarious calibration of ASTER thermal infrared bands. IEEE Transactions on Geoscience and Remote Sensing, 43, pp. 2733-2746.

Vermote, E., Tanre, D., Deuzé, J.L., and Morisette, J.J., 1997, Second Simulation of the Satellite Signal in the Solar Spectrum, 6S: An overview. IEEE transactions on Geoscience and Remote Sensing, 35(3), pp. 675-686.

Wang, Q., and TAKahashi, H., 1999, A Land Surface Water Deficit Model for an Arid and Semiarid Region: Impact of Desertification on the Water Deficit Status in the Loess Plateau, China. Journal of Climate, 12(1), pp. 244-257.

Weber, P.G., Brock, B.C., Garrett, A.J., Smith, B.W., Borel, C.C., Clodius, W. B. Bender, S.C., KaY, R.R., and Decker, M.L., 1999, MTI Mission Overview. In: Proceedings of SPIE Conference on Imaging Spectrometry V, 3753, pp. 340-346.

Weiss, M., Baret, F., Leroy, M., Hautecoeur, O., Bacour, C., Prévot, L., and Brughier, N., 2002, Validation of neural net techniques to estimate canopy biophysical variables from remote sensing data. Agronomie, 22, pp. 547-553.

Wigneron, J.P., Chanzy, A., Calvet, J.C., Olioso, A., and Kerr, Y., 2002, Modeling approaches to assimilating $\mathrm{L}$ band passive microwave observations over land surfaces. Journal of Geophysical Research-Atmospheres, 107(D14). 


\begin{abstract}
1
2 Yamaguchi, Y., Kahle, A., Tsu, H., Kawakami, T., and Pniel, M., 1998, Overview of 3 Advanced Spaceborne Thermal Emission and Reflection Radiometer (ASTER). 4 IEEE Transactions on Geoscience and Remote Sensing, 36(4), pp. 1062-1071.
\end{abstract}




\section{Figures}

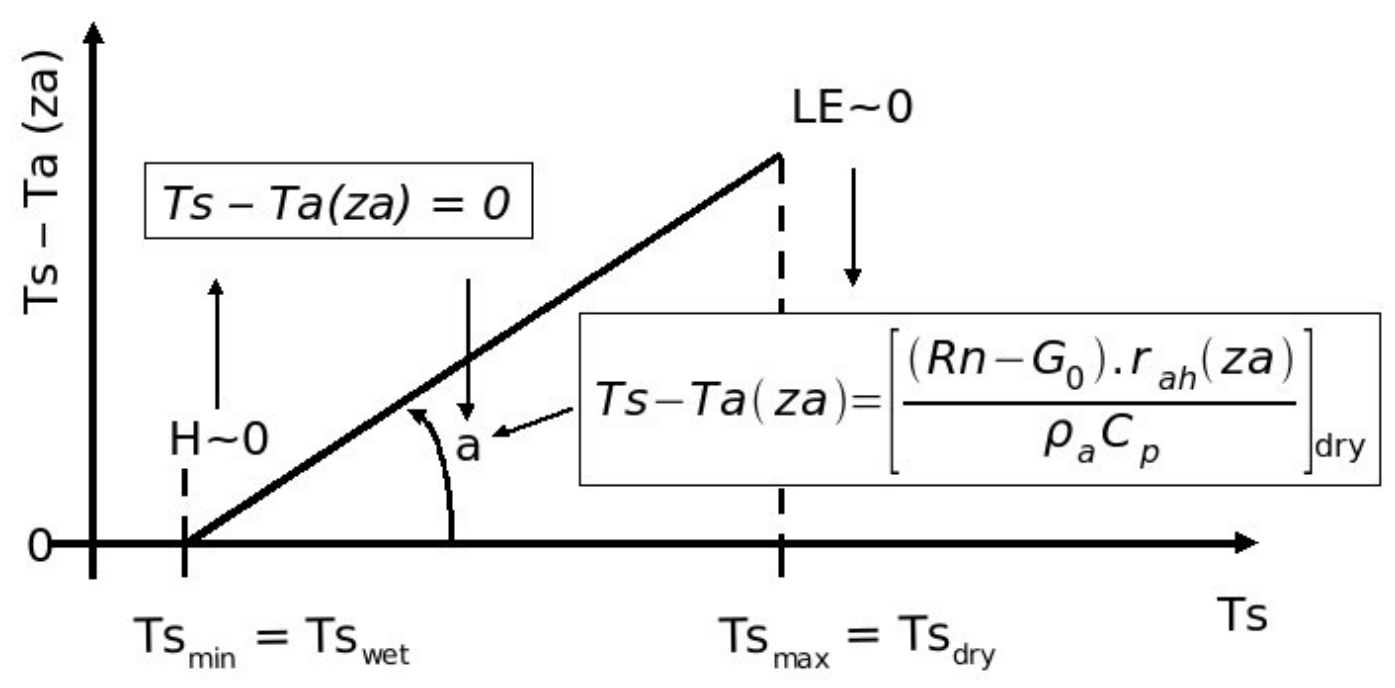

Figure 1 A linear relationship is assumed between near surface temperature gradient $T s$ - Ta, where surface temperature $T s$ is derived from remote sensing data, and air temperature $T a$ is that at the reference level ( $2 \mathrm{~m}$ above the canopy). Slope and offset of the linear relation are computed from the near surface temperature gradient Ts - Ta over wet and dry areas. $R_{n}$ is net radiation, $G_{0}$ is soil heat flux, $H$ is sensible heat flux, $L E$ is latent heat flux, $r_{a h}(z a)$ is aerodynamic resistance to sensible heat transfer, $C p$ is specific heat; and $\rho a$ is air density. $\mathrm{Ts}_{\min }$ (respectively $\mathrm{Ts}_{\max }$ ) is the lowest (respectively largest) surface temperature which occurs over the wettest (respectively the driest) areas. 

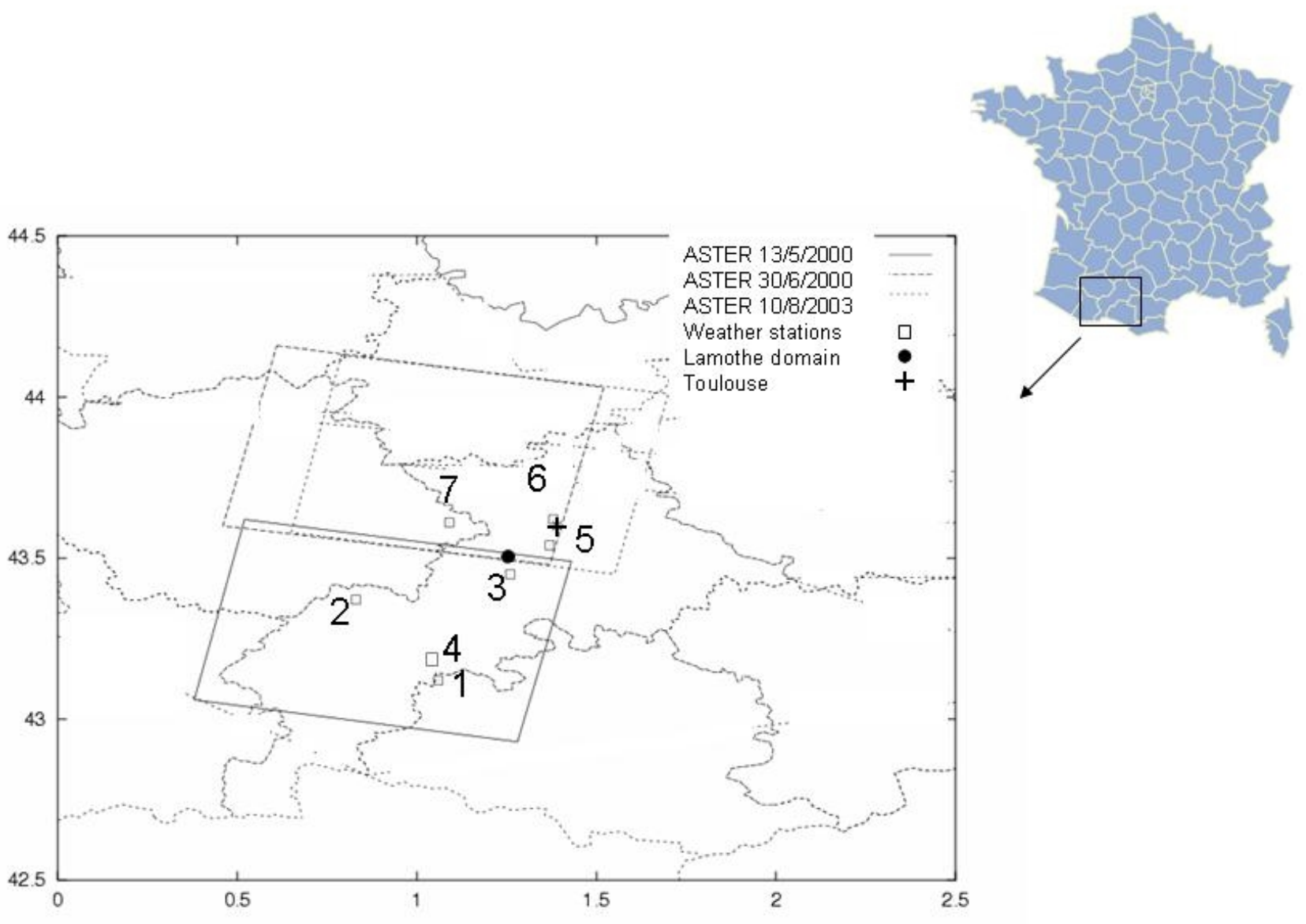

Figure 2. Location of Lamothe domain and the weather stations (numbered 1 to 7). Rectangles indicate the footprint of the three ASTER scenes used for the current study. 


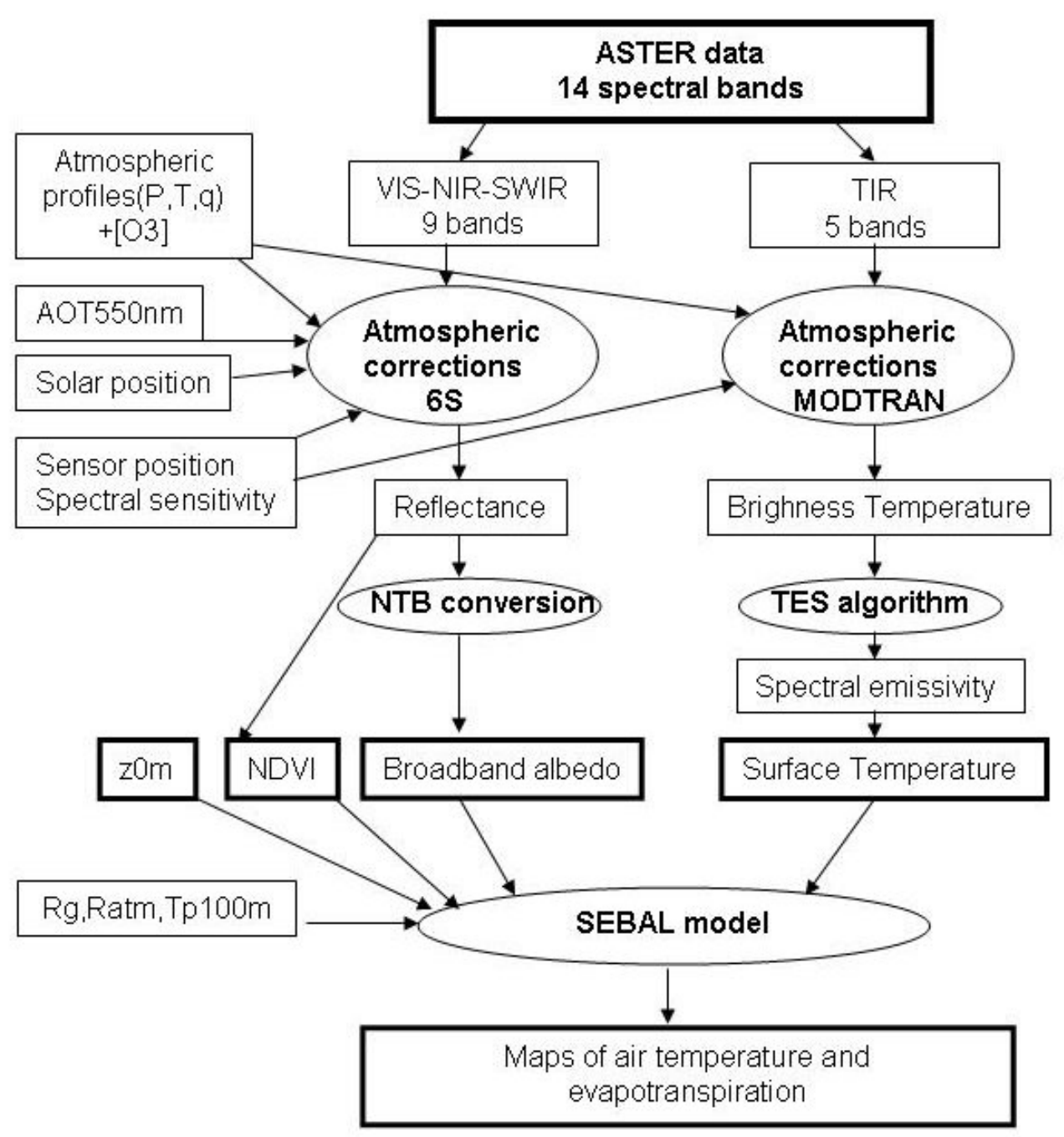

Figure 3. Flowchart of ASTER image processing, where codes, models and algorithms are in bold within ellipses. Atmospheric profiles (P: pressure, T: temperature, q: mixing ratio) were obtained from simulations of ARPEGE weather forecast model. Ozone concentration ([03]) was derived from the $6 \mathrm{~S}$ climatological dataset. Solar $(\mathrm{Rg})$ and atmospheric (Ratm) irradiances were measured from weather stations. Air potential temperature at the blending height $(\mathrm{Tp} 100 \mathrm{~m})$ was derived from simulations of ARPEGE weather forecast model. Aerosol optical thickness at $550 \mathrm{~nm}$ (AOT550nm) was derived from MODIS data. NTB means Narrowband to Broadband. TES means Temperature Emissivity Separation. NDVI means Normalized Difference Vegetation Index. Roughness length for momentum is labelled z0m. 
a)

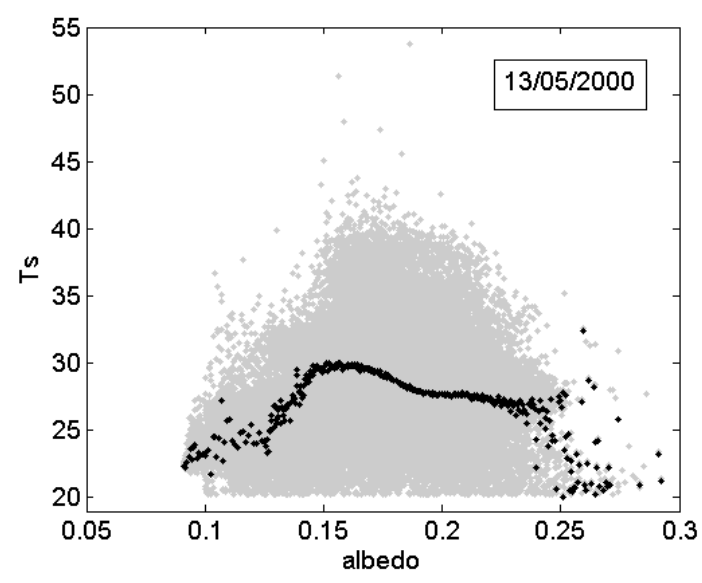

b)

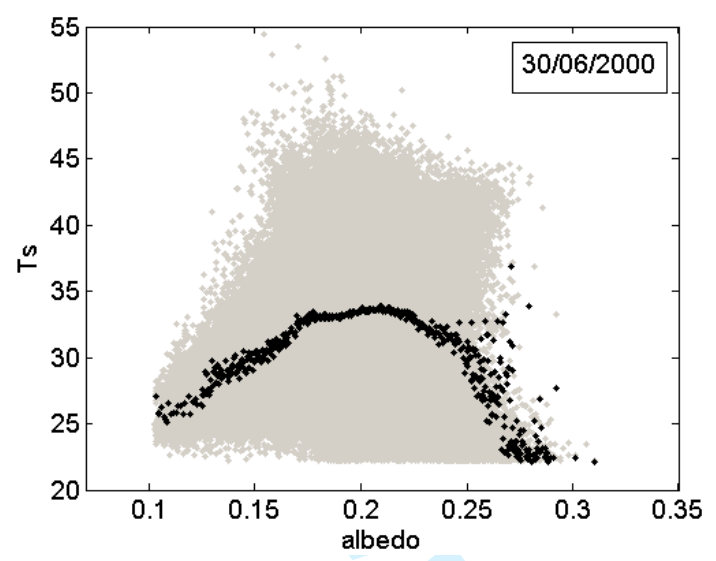

c)

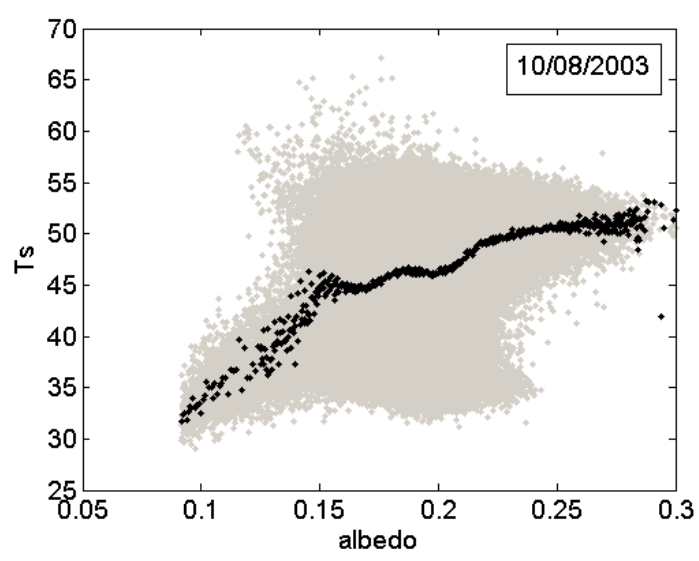

Figure 4. Evolution of radiometric surface temperature versus albedo over the study area for the three dates of ASTER data acquisition over the Lamothe domain: 13/05/2000 (a), 30/06/2000 (b) and 10/08/2003 (c). Grey points correspond to actual values from ASTER imagery (several points can be overlaid). Black points correspond to averaged values of surface temperature for albedo classes with a $1.10^{-3}$ step. 


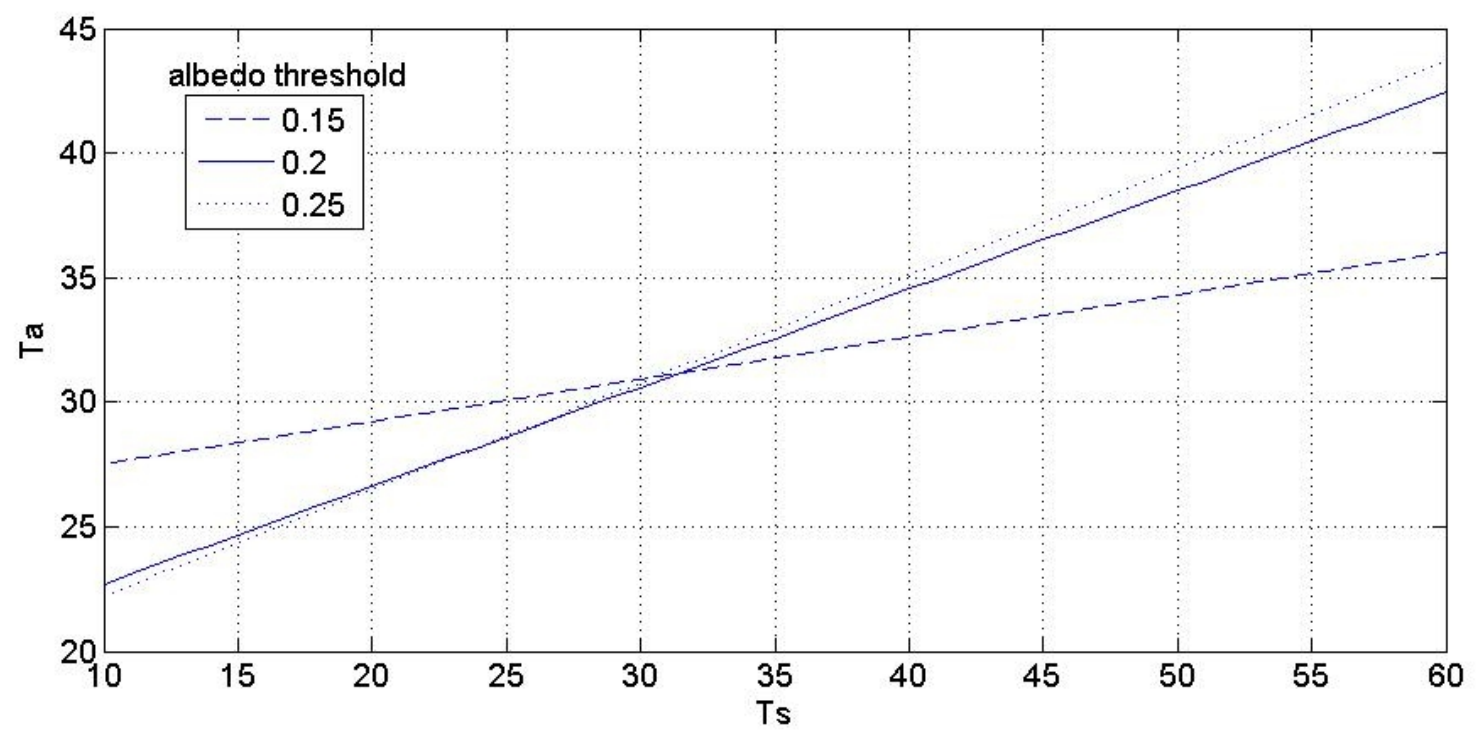

Figure 5. Relationships between surface temperature measured from ASTER and air temperature at $2 \mathrm{~m}$ above the surface simulated from SEBAL, when considering different threshold values of albedo on 10/08/2003. 


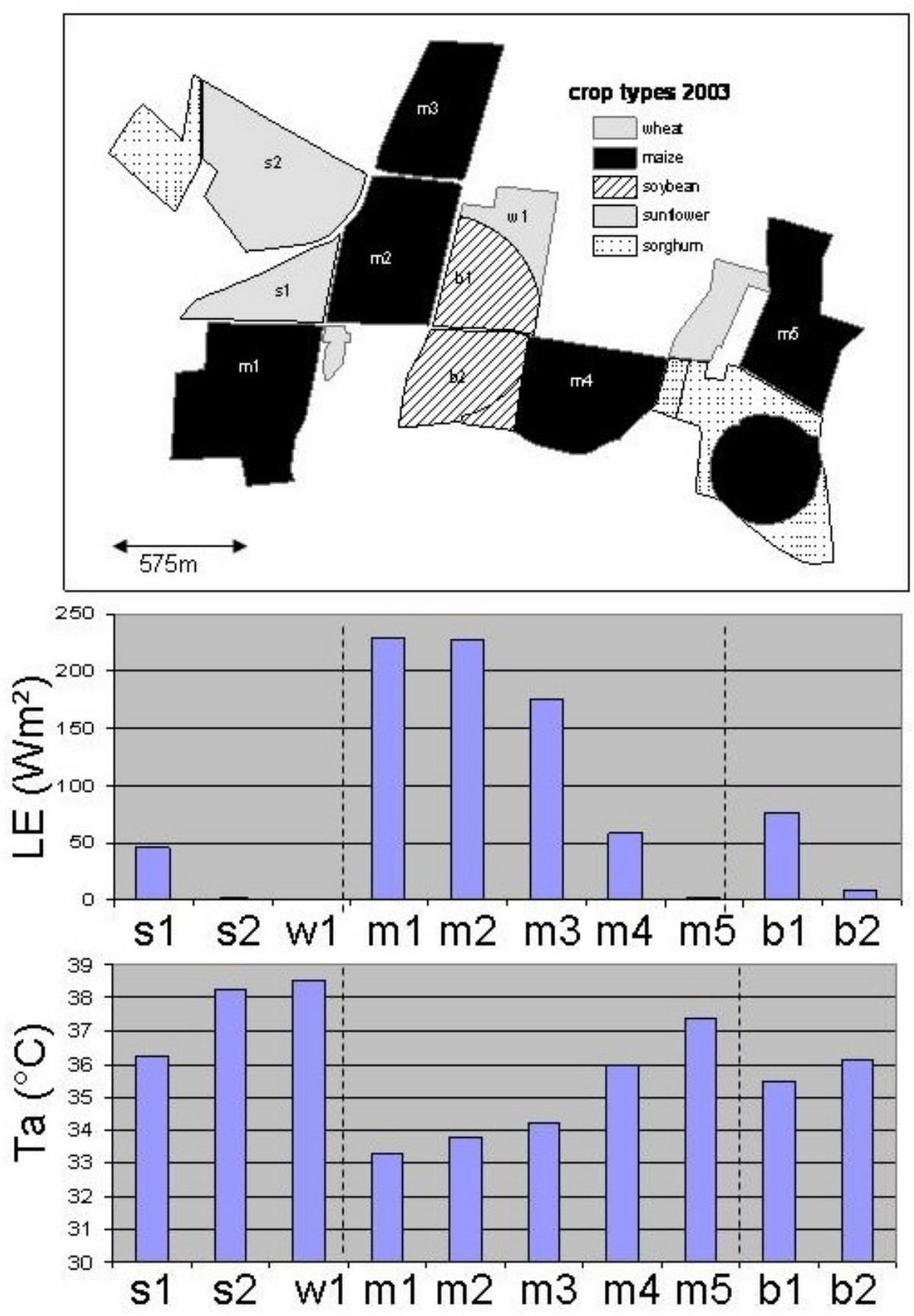

Figure 6: Mean values of SEBAL simulated air temperature (Ta) and evapotranspiration (LE) over several fields within the Lamothe domain on 10/08/2003 at 11 U.T. The irrigation dose brought for maize decreases from $196 \mathrm{~mm}$ for the $\mathrm{m} 1$ field to $100 \mathrm{~mm}$ for the $\mathrm{m} 5$ field. 


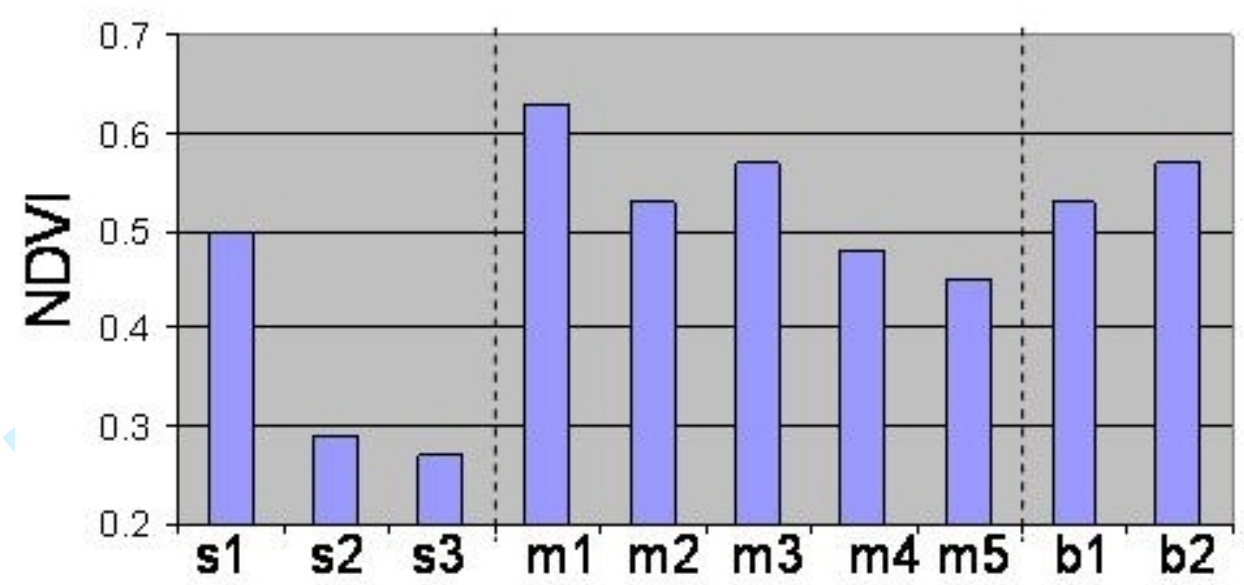

a)

b)

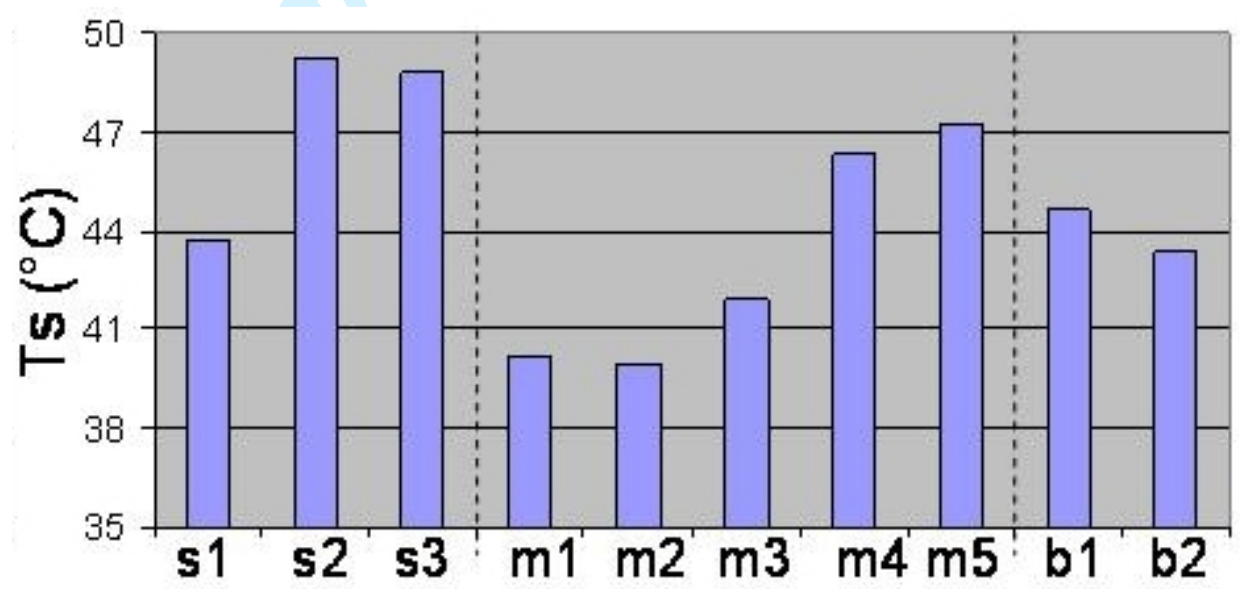

Figure 7. Mean values of NDVI (a) and Ts (b) for the several fields of the Lamothe domain on 10/08/2003. 


\section{crop types 2000}
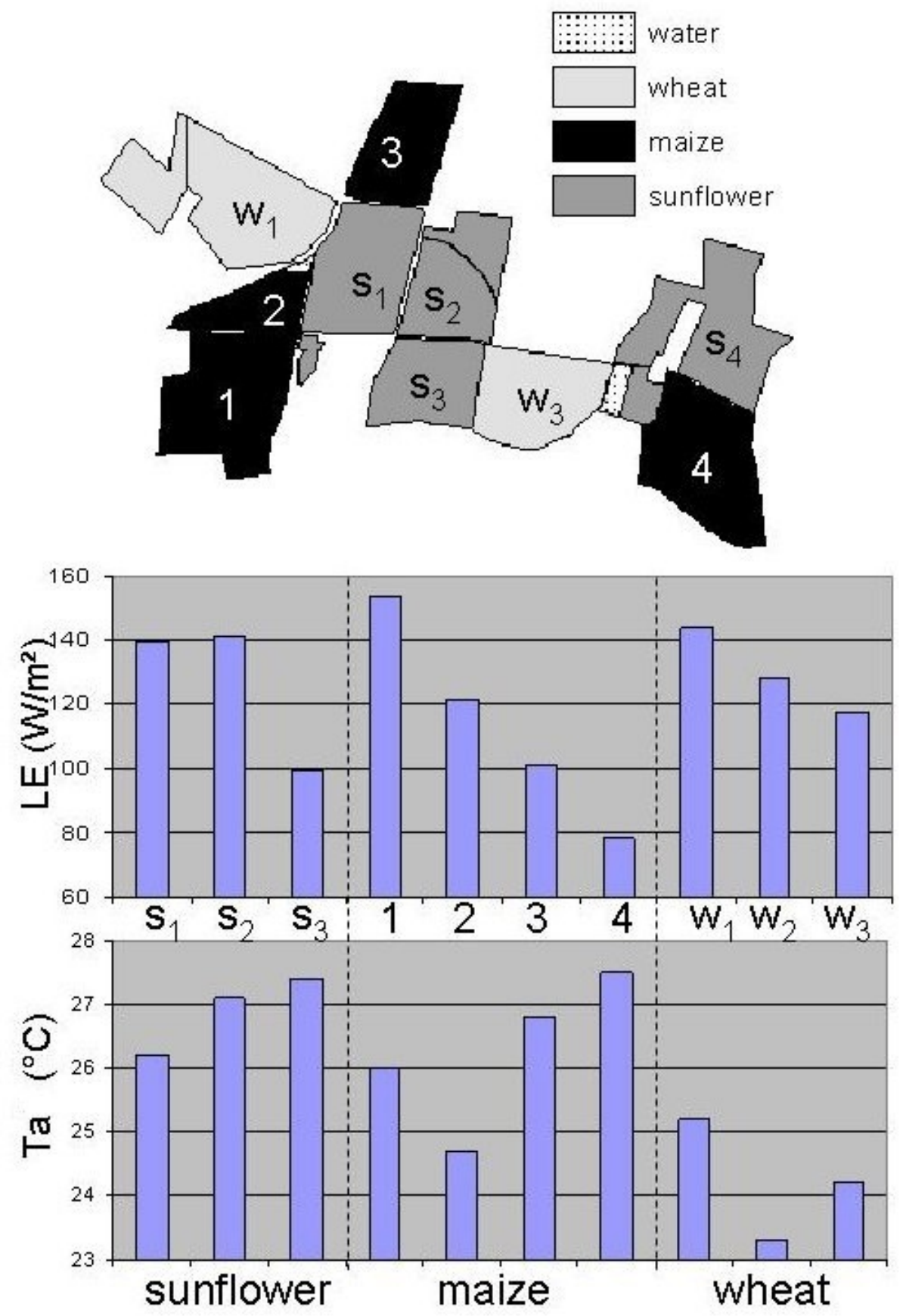

Figure 8: Mean values of SEBAL simulated air temperature (Ta) and evapotranspiration (LE) over several fields within the Lamothe domain on 13/05/2000 at 11 U.T. 


\section{Tables}

\begin{tabular}{|l|c|ccc|}
\hline Surface & $\begin{array}{l}\text { z0m (m) defined by user } \\
\text { from landuse map }\end{array}$ & $\begin{array}{l}\text { z0m (m) estimated } \\
\text { NDVI (Equation 6) }\end{array}$ & from \\
\hline Wheat-stubble & 0.026 & 0.08 & \\
Maize & 0.19 & 0.010 & \\
Sunflower & 0.13 & 0.035 & \\
Grassland & 0.026 & 0.010 & \\
Forest & 0.4 & 0.02 & \\
\hline
\end{tabular}

Table 1 Comparison, for the 10/08/2003, between values of roughness length for momentum (z0m) estimated from 1/ a landuse map and knowledge expert, and 2/ the empirically NDVI based relationship (Equation 6). At this date, wheat was harvested, and the surface was in stubble. Sunflower and corn were well developed. 


\begin{tabular}{|c|c|c|c||}
\hline Date & Location & $\begin{array}{c}\text { Air temperature } \\
\text { from weather stations } \\
\left({ }^{\circ} \mathbf{C}\right)\end{array}$ & $\begin{array}{c}\text { Air temperature } \\
\left.\text { from SEBAL ( }{ }^{\circ} \mathbf{C}\right)\end{array}$ \\
\hline $13 / 05 / 00$ & 1 & 25.0 & $24.1 \pm 0.3$ \\
\hline $13 / 05 / 00$ & 2 & 25.4 & $25.5 \pm 0.6$ \\
\hline $13 / 05 / 00$ & 3 & 26.0 & $24.8 \pm 0.4$ \\
\hline $13 / 05 / 00$ & 4 & 26.5 & $26.4 \pm 0.5$ \\
\hline $30 / 06 / 00$ & 7 & 30.5 & $34.3 \pm 1.1$ \\
\hline $10 / 08 / 03$ & 5 & 39.8 & $41.0 \pm 0.4$ \\
\hline $10 / 08 / 03$ & 6 & 39.6 & $39.3 \pm 0.7$ \\
\hline $10 / 08 / 03$ & 7 & 41.0 & $39.8 \pm 0.7$ \\
\hline
\end{tabular}

Table 2. Comparison between air temperature simulated from SEBAL ( $2 \mathrm{~m}$ above the canopy) and measured from synoptic weather stations ( $2 \mathrm{~m}$ above the surface). The SEBAL values of air temperature were averaged over 3x3 pixel windows, where the ASTER pixel spatial resolution was $90 \mathrm{~m}$. Averaged values are given along with the corresponding standard deviation values within the $3 \times 3$ pixel windows. Localisation of synoptic weather stations on ASTER imagery are indicated on Figure 2. 


\begin{tabular}{|c|c|c|}
\hline crop & field & Yield ( T / ha) \\
\hline \multirow{3}{*}{ Sunflower } & s1 & 20 \\
& $\mathrm{~s} 2$ & 10 \\
Wheat & $\mathrm{w} 1$ & 20 \\
Maize & $\mathrm{m} 1$ & 14 \\
& $\mathrm{~m} 2$ & 10 \\
& $\mathrm{~m} 3$ & 8 \\
& $\mathrm{~m} 4$ & 10 \\
& $\mathrm{~m} 5$ & 10 \\
Soybean & $\mathrm{b} 1$ & 10 \\
& $\mathrm{~b} 2$ & 10 \\
\hline
\end{tabular}

Table 3. Yields obtained for the main fields within the Lamothe Domain in 2003. 